\title{
Association of Ankle Brachial Pressure Index (ABPI) in Patients with Ischemic Stroke: A Case-Control Study
}

\author{
MOHAMMAD SELIM SHAHI ${ }^{1}$, AMINUR RAHMAN ${ }^{2}$, MD. SHAHEEN WADUD ${ }^{3}$, \\ AK TAKIB UDDIN AHMED ${ }^{4}$, UTTAM KUMAR SAHA ${ }^{5}$, ZAHED ALI $^{4}$, NARAYAN CHANDRA KUNDU ${ }^{6}$, \\ SAKHAWAT HOSSAIN ${ }^{7}$, FIROZ AHMED QURAISHI ${ }^{8}$, MD. RAFIQUL ISLAM ${ }^{9}$
}

\begin{abstract}
:
Background: Several epidemiological studies have identified the association of abnormal $A B P I$ with ischemic stroke. So the goal of this study was to determine the actual relationship of ABPI with ischemic stroke in the context of our country. Materials and Methods: This case control study was carried out in the Department of Neurology, Sir Salimullah Medical College and Mitford Hospital, Dhaka, Bangladesh. ABPI was measured by Doppler ultrasound machine of 100 patients who were admitted to the Mitford Hospital during the study period. Among them 50 patients with Ischemic stroke, confirmed by CT/MRI scan of brain were considered as 'case' and 50 age- sex matched individuals with one or more vascular risk factors (VRF) but without stroke were considered as 'control'. Then the results of ABPI were compared between the two groups. Results: Among the 50 patients with ischemic stroke (case group) , 74\% had normal ABPI and 26\% had ABPI<0.9; on the other hand among 50 age and sex matched individuals (control group) $90 \%$ had normal $\mathrm{ABPI}$ and $10 \%$ had $\mathrm{ABPI}$ $<0.9$. The difference was statistically significant between two groups $(p=<0.05)$. This association remained significant even after adjustment for potential confounders (age, gender, high BMI, hypertension, diabetes mellitus, hyperlipidemia, smoking, ischemic heart disease and family history) in a multiple logistic regression model. Conclusion: The incidence of low ABPI is significantly higher in ischemic stroke patients than the age- sex matched control.
\end{abstract}

Key words: Ischemic stroke, Ankle Brachial Pressure Index (ABPI), vascular risk factors (VRF).

\section{Introduction:}

Stroke is a major global health hazard. It is the third leading cause of death after heart disease and cancer, after the age of $40^{1}$. Annually 15 million people suffer a stroke worldwide. Of these, 5 million die and another 5 million are left permanently disabled, placing a burden on family and community ${ }^{2}$.

Stroke is defined as a clinical syndrome characterized by rapidly developing clinical symptoms and/or signs of focal and at times global loss of brain function, with symptoms lasting $>24$ hours or leading to earlier death, and with no apparent cause other than that of vascular origin ${ }^{3}$. Among the two major types, ischemic stroke comprises $85 \%$ while hemorrhagic stroke is only $15 \% .{ }^{4}$ Both intra- and extra-cranial atherosclerosis play a key role for ischemic stroke ${ }^{5}$.

The well established risk factors for ischemic stroke include advanced age, male gender, previous history of stroke, hypertension, diabetes mellitus, obesity, dyslipidemia, cigarette smoking, heart disease, transient ischemic attack, positive family history etc ${ }^{6}$. But other less studied risk markers to predict asymptomatic atherosclerosis and incident ischemic stroke should also be identified.

1. Registrar, Department of Hematology, Sir Salimullah Medical College \& Mitford Hospital, Dhaka. Bangladesh

2. Registrar, Department of Neurology, Sir Salimullah Medical College \& Mitford Hospital, Dhaka Bangladesh

3. Resident,, Department of Neurology, Sir Salimullah Medical College \& Mitford Hospital, Dhaka Bangladesh

4. Associate Professor, Department of Neurology, Sir Salimullah Medical College, Dhaka, Bangladesh.

5. Associate Professor Department of Clinical Neurology, National Institute of Neurosciences\& Hospital, Dhaka Bangladesh

6.. Associate Professor Department of Neurology, Shaheed Suhrawardy Medical College, Dhaka Bangladesh.

7. Professor, Department of Neurology, Sir Salimullah Medical College, Dhaka, Bangladesh

8. Professor Department of Interventional Neurology, National Institute of Neurosciences\& Hospital, Dhaka Bangladesh

9. Professor, Department of Neurology, Bangabandhu sheikh Mujib Medical University , Dhaka, Bangladesh 
Peripheral arterial disease (PAD) affects some 12\% to $14 \%$ of the general population, reaching $10 \%$ in people aged over 60 years and $20 \%$ aged over 75 years ${ }^{7,8}$. PAD caused by atherosclerosis is the most common cause of lower extremity ischemic syndromes in Western societies. Nearly half of those with PAD had concurrent coronary or cerebral vascular disease ${ }^{9,10}$. Even if patients with PAD are asymptomatic, they have an increased risk of future cardiac and cerebrovascular events, as well as being six times more likely to die within ten years when compared to healthy individuals. ${ }^{11}$ .The association between peripheral arterial disease and increased mortality is a result of the fact that the underlying pathological process, atherosclerosis, is a systemic one. Atherosclerosis, if present in the periphery, is also likely in other parts of the arterial tree ${ }^{12}$. The Fontaine classification provides a framework for clinical staging (from I to IV) of peripheral vascular disease $^{13}$. Although intermittent claudication is the primary and most often the only symptom of peripheral vascular disease, unfortunately a vast majority of patients are asymptomatic and undiagnosed ${ }^{14}$. As a result, relying on clinical history has a very low sensitivity for determining the presence of peripheral arterial disease ${ }^{15}$.

Therefore Ankle Brachial Pressure Index (ABPI), a simple noninvasive test done by Doppler assessment of the limb vessels to measure blood pressure in the legs relative to arms (as an approximation of central pressure), has been widely adopted for confirmation of a clinical diagnosis of peripheral arterial disease and its quantification ${ }^{16}$.

Ankle Brachial Pressure Index (ABPI) is the ratio of tibial artery systolic blood pressure to brachial artery systolic blood pressure ${ }^{17}$. The normal range of $A B P I$ is $0.91-1.3$; $A B P I>1.3$ or $<0.9$ is considered as high and low respectively; mild disease falls into the range of $0.7-0.9$, moderate disease for ratios of $0.41-0.69$ and ratios of less than or equal to 0.4 are quoted in severe disease ${ }^{18}$.

A number of groups support the use of ABPI not only as a diagnostic tool, but also as a risk assessment tool in the setting of peripheral vascular disease $^{19-21}$. In addition to diagnosing peripheral vascular disease, ABPI is also an indicator of generalized atherosclerosis because lower levels have been associated with higher rates of concomitant coronary and cerebrovascular disease, and with the presence of cardiovascular risk factors ${ }^{22}$.

Moreover, the lower the ABPI value, the higher the risk of all-cause and cardiac and cerebrovascular death in patients with peripheral vascular disease ${ }^{23}$. Similarly an elevated ABPI more than 1.30 (even if the observation was non -diagnostic because of arterial incompressibility secondary to calcification) is also a predictor for an increase in all-cause as well as cardiovascular mortality 24 .

However, some study reported a weak association between $\mathrm{ABPI}$ and ischemic stroke incidence after adjustment for other stroke risk factors ${ }^{25}$.

The goal of this case-control study was designed, therefore, to determine the association of ankle brachial pressure index (ABPI) as a risk factor for ischemic stroke.

\section{Materials and Methods:}

This prospective observational case-control study of association between ankle brachial pressure index (ABPI) in patients with ischemic stroke was conducted who were admitted in the Department of Neurology and Medicine of Sir Salimullah Medical College \& Mitford Hospital, Dhaka, Bangladesh from July 2011 to June 2012 (1 year). Fifty(50) consecutive acute ischemic stroke patients and 50 age-sex matched patients other than stroke who have one or more vascular risk factors e.g. advanced age, male gender, positive family history, hypertension, diabetes mellitus, dyslipidemia, smoking, high BMI,previous history of stroke etc. were studied. Among them the stroke patients were considered as 'case' and patients without stroke were considered as 'control'. Inclusion criteria for cases were: (1) Patients with CT /MRI scan of brain proven acute ischemic stroke. (2)Patients having athero-thrombotic stroke. (3)Patients age more than 45 years (4) patients not having hemorrhagic stroke. cardioembolic stroke, deep vein thrombosis or acute limb ischemia and hypercoagulable state. The patient's age and sex match with the cases who fulfilled the criteria for at least 1 risk factors as advanced age, male gender, positive family history, hypertension, diabetes mellitus, dyslipidemia, 
smoking, high BMI without stroke will be considered as control. Fifty clinically diagnosed patients of stroke, done by detailed history and examination, were further confirmed as having ischemic stroke by CT /MRI scan of brain. Then some relevant investigations and measurement of $\mathrm{ABPI}$ were performed. These patients were considered as case. The demographic, clinical and biochemical variables were compared with fifty age-sex matched control with appropriate statistical tools. Data were collected by a predesigned proforma. Patients information were obtained through using patients information sheets which involved questionnaire, clinical findings and biochemical findings, CT scan / MRI of brain and measurement of ABPI. All the cases and controls were informed about the nature of the study. Their informed written consent was taken in a consent form before collecting data. Proper permission was taken from the concerned departments and local ethical committee. The ABPI was measured in the Department of Cardiology of Sir Salimullah Medical College and Mitford hospital by a group of consultant cardiologists who are expert in performing Duplex vascular study by using a Doppler Echocardiography Machine (Vivid-7, general electric) with accompanying probe $(8 \mathrm{megaHz})$. All the cases and controls were informed about the nature of the study. Their informed written consent was taken in a consent form before collecting data. Statistical analyses related with this study were performed by use of SPSS 16.0 package program. The data was expressed by descriptive statistical methods like average, frequency distribution, percentage, mean \& standard deviation as applicable. Comparison between groups was done by standard statistical test e.g. Chi-square test or other tests as applicable. Correlations between numeric variables, like Lipid profile, Blood glucose, Blood pressure, BMI were investigated by Pearson correlation test.

\section{Results:}

Regarding the age distribution of the study patients, the mean age was found $62.32 \pm 7.48$ years in group I and $62.24 \pm 5.14$ years in group II. Mean difference was not statistically significant $(P>0.05)$ between two groups .

Regarding the sex distribution of the study patients, male was found $33(66.0 \%)$ in group I and $35(70.0 \%)$ in group II. Female was found $17(34.0 \%)$ and $15(30.0 \%)$ in group I and group II respectively. The difference was not statistically significant $(P>0.05)$ between the two groups .

Table-I

Age distribution of the study patients $(n=100)$

\begin{tabular}{|c|c|c|c|c|c|}
\hline \multirow[t]{2}{*}{ Age (in years) } & \multicolumn{2}{|c|}{ Group I $(n=50)$} & \multicolumn{2}{|c|}{ Group II $(n=50)$} & \multirow[t]{2}{*}{$P$ value } \\
\hline & $\mathrm{n}$ & $\%$ & $\mathrm{n}$ & $\overline{\%}$ & \\
\hline d"50 & 2 & 4.0 & 2 & 4.0 & \\
\hline $51-60$ & 24 & 48.0 & 20 & 40.0 & \\
\hline $61-70$ & 18 & 36.0 & 26 & 52.0 & \\
\hline$>70$ & 6 & 12.0 & 2 & 4.0 & \\
\hline $\begin{array}{l}\text { Mean } \pm \text { SD } \\
\text { Range (min-max) }\end{array}$ & \multicolumn{2}{|c|}{$\begin{array}{c}62.32 \pm 7.48 \\
(47-80)\end{array}$} & \multicolumn{2}{|c|}{$\begin{array}{c}62.24 \pm 5.14 \\
(50-72)\end{array}$} & $0.950^{\text {ns }}$ \\
\hline
\end{tabular}

Group I: Case, Group II: Control . ns=not significant ,P value reached from unpaired t-test

Table II

Sex distribution of the study patients $(n=100)$

\begin{tabular}{lcccccc}
\hline Sex & \multicolumn{2}{c}{ Group I $(\mathrm{n}=50)$} & & \multicolumn{2}{c}{ Group II $(\mathrm{n}=50)$} & P value \\
\cline { 2 - 3 } \cline { 5 - 6 } & $\mathrm{n}$ & $\%$ & & $\mathrm{n}$ & $\%$ & \\
\hline Male & 33 & 66.0 & & 35 & 70.0 & $0.668^{\text {ns }}$ \\
Female & 17 & 34.0 & & 15 & 30.0 & \\
\hline
\end{tabular}

$n s=$ not significant.$P$ value reached from chi-square test 
Regarding the risk factors of the study patients, previous stroke was found in 4 cases (8.0\%) in group I but not found in group II. H/O TIA was found in 2 cases $(4.0 \%)$ in group I but not found in group II. HTN was 38 cases $(76.0 \%)$ in group I and $41(82.0 \%)$ in group II. DM was 26 cases (52.0\%) and 29 cases $(58.0 \%)$ in group I and group II respectively. IHD was $10(20.0 \%)$ cases in group I and $8(16.0 \%)$ cases in group II. Family history of stroke was $17(34.0 \%)$ cases in group I and $11(22.0 \%)$ cases in group II.
Smoking/Tobacco was $37(74.0 \%)$ cases and $32(64.0 \%)$ cases in group I and group II respectively. The difference was not statistically significant $(P>0.05)$ between two groups.

$\mathrm{BMl}<23 \mathrm{~kg} / \mathrm{m} 2$ was found in $29(58.0 \%)$ patients in group I and $32(64.0 \%)$ in group II. BMI $>23 \mathrm{~kg} / \mathrm{m}^{2}$ was found in $21(42.0 \%)$ patients in group I and $18(36.0 \%)$ patients in group II (Table IV). The difference was not statistically significant $(P>0.05)$.

Table-III

Distribution of the study patients according to risk factors $(n=100)$

\begin{tabular}{|c|c|c|c|c|c|}
\hline \multirow[t]{2}{*}{ Risk factors } & \multicolumn{2}{|c|}{ Group I $(n=50)$} & \multicolumn{2}{|c|}{ Group II(n=50) } & \multirow[t]{2}{*}{ Pvalue } \\
\hline & $\mathrm{n}$ & $\%$ & $\mathrm{n}$ & $\%$ & \\
\hline \multicolumn{6}{|c|}{$\overline{\text { Previous stroke }}$} \\
\hline Yes & 4 & 8.0 & 0 & 0.0 & $0.058^{\text {ns }}$ \\
\hline No & 46 & 92.0 & 50 & 100.0 & \\
\hline \multicolumn{6}{|l|}{$\mathrm{H} / \mathrm{O} \mathrm{TIA}$} \\
\hline Yes & 2 & 4.0 & 0 & 0.0 & $0.247^{\mathrm{ns}}$ \\
\hline No & 48 & 96.0 & 50 & 100.0 & \\
\hline \multicolumn{6}{|l|}{$\mathrm{HTN}$} \\
\hline Yes & 38 & 76.0 & 41 & 82.0 & $0.461^{\mathrm{ns}}$ \\
\hline No & 12 & 24.0 & 9 & 18.0 & \\
\hline \multicolumn{6}{|l|}{ DM } \\
\hline Yes & 26 & 52.0 & 29 & 58.0 & $0.564^{\mathrm{ns}}$ \\
\hline No & 24 & 48.0 & 21 & 42.0 & \\
\hline \multicolumn{6}{|l|}{ IHD } \\
\hline Yes & 10 & 20.0 & 8 & 16.0 & $0.602^{\text {ns }}$ \\
\hline No & 40 & 80.0 & 42 & 84.0 & \\
\hline \multicolumn{6}{|c|}{ Family history of stroke } \\
\hline Yes & 17 & 34.0 & 11 & 22.0 & $0.181^{\text {ns }}$ \\
\hline No & 33 & 66.0 & 39 & 78.0 & \\
\hline \multicolumn{6}{|c|}{ Smoking/Tobacco } \\
\hline Yes & 37 & 74.0 & 32 & 64.0 & $0.279^{n s}$ \\
\hline No & 13 & 26.0 & 18 & 36.0 & \\
\hline
\end{tabular}

$\mathrm{s}=$ significant, $\mathrm{ns}=$ not significant. $\mathrm{P}$ value reached from chi-square test

Table IV

Distribution of the study patients according to BMI $(n=100)$

\begin{tabular}{|c|c|c|c|c|c|}
\hline \multirow[t]{2}{*}{$\overline{\mathrm{BMI}}\left(\mathrm{kg} / \mathrm{m}^{2}\right)$} & \multicolumn{2}{|c|}{ Group I $(n=50)$} & \multicolumn{2}{|c|}{ Group II $(n=50)$} & \multirow[t]{2}{*}{$P$ value } \\
\hline & $\mathrm{n}$ & $\%$ & $\bar{n}$ & $\overline{\%}$ & \\
\hline d"23 & 29 & 58.0 & 32 & 64.0 & $0.538^{\text {ns }}$ \\
\hline$>2321$ & 42.0 & 18 & 36.0 & & \\
\hline
\end{tabular}

$n s=$ not significant.$P$ value reached from unpaired t-test 
$\mathrm{BP}=$ Blood Pressure. Regarding the blood pressure of the study patients, mean systolic BP was found in $152.2 \pm 23.39 \mathrm{mmHg}$ in group I and $134.4 \pm 26.2 \mathrm{mmHg}$ in group II. Diastolic BP was found in $89.2 \pm 13.07$ $\mathrm{mmHg}$ and $81.2 \pm 15.14 \mathrm{mmHg}$ in group I and group II respectively. The mean difference was statistically significant $(P<0.05)$ between two groups.

Regarding the mean RBS of the study patients, in group I, RBS was found $10.05 \pm 4.49 \mathrm{mmol} / \mathrm{l}$ and in group II, RBS was $9.77 \pm 3.91 \mathrm{mmol} / \mathrm{l}$. The mean RBS difference was not statistically significant $(P>0.05)$ between two groups .

Regarding the hypercholesterolemia of the study patients, hypercholesterolemia was found in $21(42.0 \%)$ cases in group I and $14(28.0 \%)$ cases in group II. The difference was not statistically significant $(P>0.05)$ between two groups.

Regarding the $\mathrm{ABPI}$ of the study patients, normal (0.91-1.30)ABPI was found $37(74.0 \%)$ patients in group I and $45(90.0 \%)$ patients in group II. Low ABPI was found in $13(26.0 \%)$ patients in group I and $5(10.0 \%)$ patients $(n=50)$ in group II. The difference was statistically significant $(P<0.05)$ between two groups.
Mildly lower (0.70-0.90) ABPI was $9(18.0 \%)$ and $4(8.0 \%)$ in group I and group II respectively. Moderately lower (0.41-0.69) ABPI was found $4(8.0 \%)$ in group I and $1(2.0 \%)$ in group II.

Patients having IHD $3.00(95 \% \mathrm{Cl} 3.05 \%$ to $44.32 \%$ ) times more likely to have low ABPI (d"0.9).

Patients having carotid atherosclerosis 2.46 (95\% $\mathrm{Cl} 1.68 \%$ to $15.31 \%$ ) times more likely to have low ABPI (<0.9).

Patients having ischemic stroke $3.91(95 \% \mathrm{Cl}$ $1.87 \%$ to $33.18 \%$ ) times more likely to have low ABPI (<0.9).

Patients having age $>55$ years, male gender, HTN, DM, Family history of stroke, smoking/tobacco chewing, $\mathrm{BMI}>23 \mathrm{~kg} / \mathrm{m}^{2}$ and hypercholesterolemia were not statistically significant $(P>0.05)$.

Patients having carotid atherosclerosis 0.10 (95\% $\mathrm{Cl} 0.01 \%$ to $0.53 \%$ ) times more likely to have ischemic stroke. Patients having low ABPI 7.91 $(95 \% \mathrm{Cl} 1.58 \%$ to $39.49 \%)$ times more likely to have ischemic stroke. Patients having age $>55$ years, male gender, HTN, DM, IHD, Family history of stroke, smoking/tobacco, BMl>23 kg/m² and hypercholesterolemia were not statistically significant $(P>0.05)$ (Table $X)$.

Table-V

Distribution of the study patients according to Blood Pressure $(n=100)$

\begin{tabular}{lccc}
\hline Blood pressure $(\mathrm{mmHg})$ & Group I $(\mathrm{n}=50)$ & Group II $(\mathrm{n}=50)$ & P value \\
& Mean \pm SD & Mean \pm SD & \\
\hline Systolic & $152.2 \pm 23.39$ & $134.4 \pm 26.2$ & $0.001^{\mathrm{s}}$ \\
Range (min-max) & $(110-200)$ & $(100-190)$ & \\
Diastolic & $89.2 \pm 13.07$ & $81.2 \pm 15.14$ & $0.001^{\mathrm{s}}$ \\
Range (min-max) & $(70-120)$ & $(60-120)$ & \\
\hline
\end{tabular}

$s=$ significant.$P$ value reached from unpaired $t$-test

Table-VI

Distribution of the study patients according to Random blood sugar ( $n=100)$

\begin{tabular}{lccc}
\hline & Group I $(\mathrm{n}=50)$ & Group II $(\mathrm{n}=50)$ & $P$ value \\
& Mean \pm SD & Mean \pm SD & \\
\hline RBS $($ mmol/l) & $10.05 \pm 4.49$ & $9.77 \pm 3.91$ & $0.740^{\text {ns }}$ \\
Range $($ min-max $)$ & $(5.2-21)$ & $(5.4-19)$ & \\
\hline
\end{tabular}

RBS=Random blood sugar .ns= not significant.$P$ value reached from unpaired t-test 
Table-VII

Distribution of the study patients according to hypercholesterolemia $(n=100)$

\begin{tabular}{lcccccc}
\hline Hypercholesterolemia & \multicolumn{2}{c}{ Group I $(\mathrm{n}=50)$} & & \multicolumn{2}{c}{ Group II $(\mathrm{n}=50)$} & P value \\
\cline { 2 - 3 } & $\mathrm{n}$ & $\%$ & & $\mathrm{n}$ & $\%$ & \\
\hline Yes & 21 & 42.0 & & 14 & 28.0 & $0.142^{\text {ns }}$ \\
No & 29 & 58.0 & & 36 & 72.0 & \\
\hline
\end{tabular}

ns $=$ no significant.$P$ value reached from Chi-square test

Table-VIII

Distribution of the study patients according to ankle brachial pressure index (ABPI) $(n=100)$

\begin{tabular}{|c|c|c|c|c|c|}
\hline \multirow{2}{*}{$\overline{\mathrm{ABPI}}$} & \multicolumn{2}{|c|}{ Group I $(n=50)$} & \multicolumn{2}{|c|}{ Group II $(n=50)$} & \multirow[t]{2}{*}{$P$ value } \\
\hline & $n$ & $\%$ & $\mathrm{n}$ & $\%$ & \\
\hline Normal (0.91-1.30) & 37 & 74.0 & 45 & 90.0 & $0.037^{\mathrm{s}}$ \\
\hline \multirow[t]{4}{*}{ Low } & 13 & 26.0 & 5 & 10.0 & \\
\hline & Mild (0.70-0.90) & 9 & 18.0 & 4 & $8.0-$ \\
\hline & Moderate $(0.41-0.69)$ & 4 & 8.0 & 1 & $2.0-$ \\
\hline & Severe $(<0.40)$ & 0 & 0.0 & 0 & 0.0 \\
\hline
\end{tabular}

$s=$ significant.$P$ value reached from unpaired t-test

Table-IX

Multiple logistic regression models for risk factors associated with low ABPI (d"0.9).

\begin{tabular}{lcccc}
\hline & OR & \multicolumn{2}{c}{$95.0 \%$ Cl for OR } & P value \\
\cline { 3 - 4 } & & Lower & Upper & \\
\hline Age $>$ 55 years & 0.25 & 0.00 & 9.34 & $0.453^{\mathrm{ns}}$ \\
Male gender & 1.07 & 0.14 & 7.48 & $0.979^{\mathrm{ns}}$ \\
HTN & 0.102 & 0.00 & 2.370 & $0.155^{\mathrm{ns}}$ \\
DM & 1.18 & 0.14 & 9.51 & $0.872^{\mathrm{ns}}$ \\
IHD & 3.00 & 3.05 & 44.32 & $0.005^{\mathrm{s}}$ \\
F/H of stroke & 0.99 & 0.17 & 5.77 & $0.991^{\mathrm{ns}}$ \\
Smoking /tobacco & 2.23 & 0.25 & 19.46 & $0.466^{\mathrm{ns}}$ \\
BMI (>23 kg/m ${ }^{2}$ ) & 0.52 & 0.09 & 2.84 & $0.453^{\mathrm{ns}}$ \\
Hypercholesterolemia & 3.79 & 0.55 & 26.00 & $0.174^{\mathrm{ns}}$ \\
Carotid Atherosclerosis & 2.46 & 1.68 & 15.31 & $0.026^{\mathrm{s}}$ \\
Ischemic stroke & 3.91 & 1.87 & 33.18 & $0.002^{\mathrm{s}}$ \\
\hline
\end{tabular}

$\mathrm{s}=$ significant; ns=not significant 
Table-X

Multiple logistic regression models for risk factors associated with Ischemic stroke.

\begin{tabular}{lcccc}
\hline & OR & \multicolumn{2}{c}{$95.0 \%$ Cl for OR } & P value \\
\cline { 3 - 4 } & & Lower & Upper & \\
\hline Age $>$ 55 years & 0.75 & 0.16 & 3.41 & $0.716^{\text {ns }}$ \\
Male gender & 0.43 & 0.11 & 1.68 & $0.225^{\text {ns }}$ \\
HTN & 0.98 & 0.21 & 4.47 & $0.983^{\text {ns }}$ \\
DM & 0.53 & 0.14 & 2.01 & $0.358^{\text {ns }}$ \\
IHD & 0.28 & 0.04 & 1.73 & $0.173^{\text {ns }}$ \\
F/H of stroke & 1.79 & 0.47 & 6.77 & $0.389^{\text {ns }}$ \\
Smoking/tobacco & 2.34 & 0.56 & 9.69 & $0.239^{\text {ns }}$ \\
BMI $\left(>23 k g / m^{2}\right)$ & 1.04 & 0.30 & 3.61 & $0.946^{\text {ns }}$ \\
Hypercholesterolemia & 1.47 & 0.46 & 4.69 & $0.508^{\text {ns }}$ \\
Carotid Atherosclerosis & 0.10 & 0.01 & 0.53 & $0.007^{\mathrm{s}}$ \\
Low ABPI $(<0.9)$ & 7.91 & 1.58 & 39.49 & $0.012^{\mathrm{s}}$ \\
\hline
\end{tabular}

s=significant; ns=not significant .

\section{Discussion:}

An $\mathrm{ABPI}$ ratio of less than 0.9 has been associated with up to a three-fold relative increase in cardiovascular mortality like ischemic stroke, IHD in both men and women $7,22,27$. Similarly, having an elevated $\mathrm{ABPI}>1.40$ is a predictor for an increase in all-cause mortality as well as cardiovascular mortality like stroke and $I H D^{28}$.

However, relatively few data exist on the relationship between $\mathrm{ABPI}$ and stroke, and those studies have presented conflicting results, some showing that low ABPI independently predicted stroke risk, while other studies did not find such an association ${ }^{20,32}$. Furthermore, many of these studies were focused largely on a single race, gender, or a narrowly defined age group ${ }^{29-31}$. For these discrepancies the current study was conducted to evaluate the association of $\mathrm{ABPI}$ with ischemic stroke in the Bangladeshi population.

A total of 100 consecutive patients were enrolled in this study, out of which 50 patients with acute ischemic stroke and 50 patients having other than stroke were considered as group I (case) and group II (control) respectively. The present study findings were discussed and compared with previously published relevant studies.

In this current study in Table I was observed that the mean age was found $62.32 \pm 7.48$ years with range from 47 to 80 years in group I and $62.24 \pm 5.14$ years with range from 50 to 72 years in group II, which was almost similar between two groups. Most of the subjects were in 6th and 7th decade in both groups exploring that the association of low ABPI with ischemic stroke increase with age $^{33}$. In a Thai study showed the mean age of all ischemic stroke patients was $63.5 \pm 14$ years, $70.3 \pm 14.6$ years in patients with abnormal ABPI and $61.9 \pm 13.4$ years in patients with normal $\mathrm{ABPI}^{34}$. Another study obtained the mean age was $64.04 \pm 12.24$ years in patients with normal ABPI and $70.48 \pm 11.78$ years in patients with abnormal $A B P{ }^{35}$. A recent study showed that the median age was 64 years with range from 55 to 73 years in patients with normal $\mathrm{ABPI}$ and 71 years with range from 63 to 77 years in patients with abnormal $\mathrm{ABPI}^{36}$. The above findings are compatible with the current study.

In Table II regard showed that the sex incidence of the present study, it was observed that male was found $66.0 \%$ in group I and $70.0 \%$ in group II. A series of studies showed that male to female ratio was almost 2:1 in the whole study patients and male sex was associated with plaque score independently of other risk factors. ${ }^{35-38}$ Similarly, male predominance also obtained ${ }^{38}$.

Table III showed that the risk factors of the study patients, where previous stroke was found in 
4(8.0\%) patients in group I and H/O TIA was found in $2(4.0 \%)$ patients in group I but not found in group II. HTN was $38(76.0 \%)$ patients in group I and $41(82.0 \%)$ patients in group II. DM was $26(52.0 \%)$ patients and $29(58.0 \%)$ patients in group I and group II respectively. IHD was $10(20.0 \%)$ patients in group I and $8(16.0 \%)$ patients in group II. Family history of stroke was $17(34.0 \%)$ patients in group I and $11(22.0 \%)$ patients in group II. Smoking/Tobacco was $37(74.0 \%)$ patients and $32(64.0 \%)$ patients in group I and group II respectively. In a study documented that older age, previous history of stroke, TIA, diabetes mellitus, hypertension, ischemic heart disease, smoking and high BMl were considered as significant risk factors of stroke and abnormal $\mathrm{ABP}^{22}$. In this series it was observed that previous stroke, H/O TIA, HTN, DM, IHD, positive family history of stroke and smoking / Tobacco chewing $c$ were almost similar between two groups, no statistically significant $(P>0.05)$ difference was found between the groups. Similar observations regarding the risk factors of stroke were also made $30,37,40$.

For Asian people, BMI $>23 \mathrm{~kg} / \mathrm{m}^{2}$ was considered as high $\mathrm{BMI}^{41}$. In Table IV this current study it was observed that BMI d" $23 \mathrm{~kg} / \mathrm{m}^{2}$ was found in $58.0 \%$ patients in group I and $64.0 \%$ in group II. BMI $>23$ $\mathrm{kg} / \mathrm{m}^{2}$ was found in $42.0 \%$ in group I and $36.0 \%$ in group II. The difference was not statistically significant $(P>0.05)$. A recent study mentioned that there were $7.4 \%$ patients who showed abnormal $\mathrm{ABI}(<0.90)$, and these patients were typically older and had a lower $\mathrm{BMI}^{37}$. In an another study it was observed that $75.0 \%$ and $72.7 \%$ patients were overweight in group I (stroke patients) and group II (control) respectively ${ }^{40}$.

From Table $\mathrm{V}$ of this present study it was observed that the mean systolic blood pressure was found $152.2 \pm 23.39 \mathrm{mmHg}$ varied from 110 to $200 \mathrm{mmHg}$ in group I and $134.4 \pm 26.2 \mathrm{mmHg}$ varied from 100 to $190 \mathrm{mmHg}$ in group II. The mean systolic blood pressure was significantly $(p<0.001)$ higher in group I patients. On the other hand the mean diastolic blood pressure was found $89.2 \pm 13.07$ $\mathrm{mmHg}$ varied from 70 to $120 \mathrm{mmHg}$ in group I and $81.2 \pm 15.14 \mathrm{mmHg}$ varied from 60 to $120 \mathrm{mmHg}$ in group II. The mean diastolic blood pressure was significantly $(p<0.001)$ higher in group I patients. But the presence of hypertension had no significant difference between two groups. This may be due to reactionary hypertension which occurs immediately after the stroke. These findings gave the emphasis over the blood pressure control as preventive measures of stroke and other cardiovascular events. The higher mean systolic and diastolic BP were also observed, where the mean systolic BP was found $173.0 \pm 16.0 \mathrm{mmHg}$ and $162.0 \pm 8.0 \mathrm{mmHg}$ in group I and group II respectively. ${ }^{38}$ Similarly, the mean diastolic BP was found $98.0 \pm 8.0 \mathrm{mmHg}$ in group I and $101.0 \pm 8 \mathrm{mmHg}$ in group II, which are comparable with the current study.

In Table VI of this current series it was observed that the mean Random blood sugar (RBS) was found $10.05 \pm 4.49 \mathrm{mmol} / \mathrm{l}$ and $9.77 \pm 3.91 \mathrm{mmol} / \mathrm{l}$ in group I and group II respectively, which were almost similar between two groups. A recent study mentioned that there was a significant association of random blood sugar which was found $11.05 \pm 4.4$ and $8.77 \pm 3.91 \mathrm{mmol} / \mathrm{l}$ in group I and group II respectively, which are comparable with the current study ${ }^{41}$.

In Table VII this present series it was observed that hypercholesterolemia was found $42.0 \%$ in group I and $28.0 \%$ in group II, that was higher in group I but not statistically significant $(P>0.05)$ between two groups. Similarly, a recrnt study showed hypercholesterolemia $40.3 \%$ in their study patients, which is similar with the current study. ${ }^{43}$ In another studydocumented hypercholesterolemia $42.4 \%$ and $14.3 \%$ patients in group I (stroke patients) and group II (control) respectively, which is closely resembled with the current study ${ }^{42}$.

In Table VIII Duplex study of the carotid arteries shows carotid arthrosclerosis was significantly higher in group I, where almost one third (32.0\%) of the group I patients had atherosclerosis in the carotid arteries proved by the carotid artery duplex study and only $12.0 \%$ of group II patients had carotid atherosclerosis. Mild atherosclerosis was found $11(22.0 \%)$ patients in group I and $5(10.0 \%)$ patients in group II. Moderate atherosclerosis was $4(8.0 \%)$ patients in group I and $1(2.0 \%)$ patients 
in group II. Severe atherosclerosis was $1(2.0 \%)$ patients in group I but not found in group II. The difference was statistically significant $(P<0.05)$ between two groups. This indicates that the presence of carotid atherosclerosis was significantly associated with stroke. The finding of this present study was congruent with previous studies where severe extracranial disease was significantly associated with the incidence of ischemic stroke ${ }^{36,43}$. In Table IX, the Ankle Brachial Pressure Index (ABPI), it was observed that normal $(0.91$ - 1.30) ABPI was found nearly three fourth $(74.0 \%)$ in group I patients and $90.0 \%$ in group II. Low ABPI was found more than one fourth $(26.0 \%)$ in group I and $10.0 \%$ in group II. Low ABPI was significantly $(p=0.037)$ higher in group I patients. It indicates that ischemic stroke was associated with low ABPI. Mildly lower (0.70-0.90) ABPI was $18.0 \%$ and $8.0 \%$ in group I and group II respectively. Moderately lower (0.41-0.69) ABPI was found $8.0 \%$ in group I and $2.0 \%$ in group II. Similarly, in a study reported that low ABPI was strongly associated with increased incidence of ischemic stroke ${ }^{44}$. In another study also showed significant association of ischemic stroke with low $\mathrm{ABPI}$, which was similar with the current study; but the percentage of the low ABPI of the current study patients with stroke was higher $(26.0 \%)$ with the above mentioned study (12.7\%), which may be due to the ethnic variation ${ }^{45}$. In Singapore general hospital a study done and found that $26.0 \%$ patients with low ABPI have incident stroke, which is closely resembled with the current study. ${ }^{36} \mathrm{In}$ Asian people, possibly the prevalence of low ABPI is higher than the European people, although this should be determined in a large scale observational study in the Asian community. There might be another possibility that the current study and Singapore study were hospital based study and the American study was done in the community. This might be the cause of higher prevalence of low ABPI in these studies.

In Table $X$ of this current study, it was observed in multiple logistic regression model that the patients who had ischemic stroke will have 3.91 times more likely to have low ABPI (d"0.9) with $95 \% \mathrm{Cl} 1.87 \%$ to $33.18 \%$; $(p<0.05)$. Patients who had IHD will have 3.0 times more likely to have low ABPI (d"0.9) with $95 \% \mathrm{Cl} 3.05 \%$ to $44.32 \%$; $(p<0.05)$. Patients who had carotid atherosclerosis will have 2.46 times more likely to have low ABPI (d"0.9) with $95 \% \mathrm{Cl}$ $1.68 \%$ to $15.31 \%$; $(p<0.05)$. On the other hand, patients with age $>55$ years, male gender, HTN, $\mathrm{DM}$, family history of stroke, smoking/tobacco chewing, $\mathrm{BMl}>23 \mathrm{~kg} / \mathrm{m}^{2}$ and hypercholesterolemia were not statistically significant $(P>0.05)$ with low $A B P I$ in multivariate logistic model. In a recent study performed multivariate regression among ischemic patients and found that older age, hypertension, coronary disease, elevated systolic blood pressure, as well as low and borderline ABIs were all significantly associated with stroke $e^{45}$.

In Table XI of this present study, it was observed in the multiple logistic regression model that the patients who had low ABPI will have 7.91 times more likely to have ischemic stroke with $95 \% \mathrm{Cl}$ $1.58 \%$ to $39.49 \%$; $(p<0.05)$. Patients who had carotid atherosclerosis will have 0.10 times more likely to have ischemic stroke with $95 \% \mathrm{Cl} 0.01 \%$ to $0.53 \%$; $(p<0.05)$.. Whereas patients with $>55$ years, male gender, HTN, DM, IHD, Family history of stroke, smoking / tobacco chewing, BMI (>23 $\mathrm{kg} / \mathrm{m}^{2}$ ) and hypercholesterolemia were not significantly $(P>0.05)$ associated in multivariate logistic model. In a recent study found that after multivariate analysis, ischemic stroke was significantly correlated with abnormal ABI (OR 1.85; Cl 1.05-3.28; $P=0.033$ ); male gender (OR 1.45; $\mathrm{Cl} 1.08-1.95 ; \mathrm{P}=0.014)$ and age e"60 years (OR $3.71 ; \mathrm{Cl} 2.63-5.24 ; \mathrm{P}=0.001)$. The above findings are consistent with a current study 35 .

In the Strong Heart Study the association between high $A B I$ and mortality was similar to that of low $A B I$ and mortality, highlighting a U-shaped association between this noninvasive measure of peripheral arterial disease and mortality risk. Death from all causes occurred in $23.3 \%$ of the study subjects and of these, $26.6 \%$ were attributable to cerebrovascular disease and Low $\mathrm{ABI}$ was present in $4.9 \%$, and high $\mathrm{ABI}$ occurred in $9.2 \% 45$. But the above mentioned findings were inconsistent with the findings of the current study. 


\section{Conclusion:}

The present study data was showing a link between low ABPI with IHD, carotid atherosclerosis and ischemic stroke. So there is significant association of low Ankle Brachial Pressure Index (ABPI) in patients with Ischemic Stroke:

Disclosure: Conflict of interest: none

\section{References:}

1. Ropper AH, Samuels MA. Cerebrovascular diseases, in Adams and Victor's Principles of Neurology, 9th edn. McGraw-Hill Company, New York, 2009; 746-5.

2. World health report-2002, World Health Organization.

3 Hatano S. Experience from a multicentre stroke register: a preliminary report. Bull World Health Organ, 1976; 54:541-3.

4. Rothwell PM, Coull AJ, Giles MF. Change in stroke incidence, mortality, case-fatality, severity and risk factors in UK from 1981 to 2004 (Oxford Vascular Study). Lancet, 2004; 363: 1925-33.

5. Nowik $M$, Dreschler $H$, Nowacki $P$. Atherosclerotic plaque instability and ischemic stroke: the role of inflammatory and immunologic factors. Neurol Neurochir Pol. 2004; 38(3): 209-14.

6. Sacco RL, Benjamin EJ, Broderick JP, Dyken M, Easton JD, Feinberg WM. et al., American Heart Association Prevention Conference IV. Prevention and Rehabilitation of Stroke, Risk factors. Stroke, 1997;28: 1507-17.

7. Criqui $M$, Langer R, Fronek A. Mortality over a period of 10 years in patients with peripheral arterial disease. $\mathrm{N}$ Engl $\mathrm{J}$ Med, 1992; 326:381-6.

8. Selvin E, Erlinger TP. Prevalence of and risk factors for peripheral arterial disease in the United States: Results from the National Health and Nutrition Examination Survey, 1999-2000. Circulation, 2004;110: 738-43.

9. Criqui M, Denenberg J, Langer R. The epidemiology of peripheral arterial disease: importance of identifying the population at risk. Vasc Med, 1997;2: 221-6.
10. Higgins JP, Higgins JA. Peripheral arterial disease_-part I. Diagnosis, epidemiology and risk factors. J Okla State Med Assoc, 2002; 95, 765-9.

11. Priollet P. Quality of life and peripheral arterial disease: perspectives for the future. Drugs, 1998; 56(Suppl 3):49-58

12. Ness J, Aronow WS, Newkirk E. Prevalence of symptomatic peripheral arterial disease, modifiable risk factors, and appropriate use of drugs in the treatment of peripheral arterial disease in older persons seen in a university general medicine clinic. J Gerontol, 2005;60: 255-7.

13. Dormandy JA, Rutherford RB. Management of peripheral arterial disease. TASC Working Group. J Vasc Surg, .2000; 31:S1-S296.

14. Mc Dermott MM, Mehta S, Greenland P. Exertional leg symptoms other than intermittent claudication are common in peripheral arterial disease. Arch Intern Med, 159, 1999; 387-32.

15. Marinelli MR, Beach KW, Glass MJ, Primozich JF, Strandness DE. Noninvasive testing vs clinical evaluation of arterial disease: a prospective study. JAMA, 1979; 241: 2031-34.

16. Johnston KW, Hosang MY, Andrews D.F. Reproducibility of noninvasive vascular laboratory measurements in the peripheral circulation. J Vasc Surg, 1987; 6:147-51.

17. Schroll M, Munck $O$. Estimation of peripheral arteriosclerotic disease by ankle blood pressure measurements in a population study of 60-year-old men and women. J Chronic Dis, 1981;34(6): 261-69.

18. American Diabetes Association. Peripheral arterial disease in people with diabetes. Diabetes Care, 2003; 26: 3333-41.

19. Sikkink CJ, van Asten, WN, van't Hof, MA, van Langen $\mathrm{H}$, van der Vliet JA. Decreased ankle/brachial indices in relation to morbidity and mortality in patients with peripheral arterial disease. Vasc Med, 1972:169-73.

20. Newman AB, Shemanski L, Manolio TA. Anklearm index as a predictor of cardiovascular 
disease and mortality in the Cardiovascular Health Study. Arterioscler Thromb Vasc Bio, 1999:538-45.

21. Papamichael CM, Lekakis JP, Stamatelopoulos $\mathrm{KS}$. Ankle-brachial index as a predictor of the extent of coronary atherosclerosis and cardiovascular events in patients with coronary artery disease. Am J Cardiol, 2000; 86: 615-18.

22. Newman AB, Sutton-Tyrrell K, Vogt MT, Kuller $\mathrm{LH}$, Morbidity and mortality in hypertensive adults with a low ankle/arm blood pressure index. JAMA, 1993 270: 487-89.

23. Feringa $\mathrm{HH}$, Bax JJJ, van Waning $\mathrm{VH}$. Virgin $\mathrm{H}$,Boersma $\mathrm{E}$, Elhendy A et al. The long-term prognostic value of the resting and post exercise ankle-brachial index. Arch Intern Med, 2006; 166(5): 529-35.

24. Resnick HE, Lindsay RS, McDermott MM et al. Relationship of high and low ankle brachial index to all-cause and cardiovascular disease mortality: the Strong Heart Study. Circulation, 2004;109:733-9.

25. Leng GC, Fowkes FG, Lee AJ, Dunbar J, Housley E, Ruckley CV, Use of ankle brachial pressure index to predict cardiovascular events and death: a cohort study. BMJ, 1996; 313:1440-44.

26. Thiele BL, Jones AM, Hobson RW, Bandyk DF, Baker WH, Sumner DS, et al. Standards in noninvasive cerebrovascular testing. Report from the Committee on Standards for Noninvasive Vascular Testing of the Joint Council of the Society for Vascular Surgery and the North American Chapter of the International Society for Cardiovascular Surgery. J Vasc Surg, 1992; 15:495-503.

27. Mc Kenna M, Wolfson S, Kuller L. The ratio of ankle and arm arterial pressure as an independent predictor of mortality. Atherosclerosis, 1991; 87 :119-28.

28. Resnick HE, Lindsay RS, McDermott MM. Relationship of high and low ankle brachial index to all-cause and cardiovascular disease mortality: the Strong Heart Study. Circulation, 2004; 109 :733-39.

29. Murabito JM, Evans JC, Nieto K. Prevalence and clinical correlates of peripheral arterial disease in the Framingham Offspring Study. Am Heart J, 2002; 143:961-65.

30. Abbott RD, Rodriguez BL, Petrovitch $\mathrm{H}$, Yano, K, Schatz IJ, Popper JS., et al. Ankle-brachial blood pressure in elderly men and the risk of stroke: the Honolulu Heart Program. J Clin Epidemiol, 2001; 54(10):973-8.

31. Sutton-Tyrrell K, Venkitachalam L, Kanaya AM, Boudreau R, Harris T, Thompson T, et al. Relationship of ankle blood pressures to cardiovascular events in older adults. Stroke, 2008; 39(3): 863-9.

32. Tsai AW, Folsom AR, Rosamond WD, Jones DW. Ankle-brachial index and 7-year ischemic stroke incidence: the ARIC study. Stroke, 2001;32:1721-4.

33. Allison MA, Ho E, Denenberg JO, Ethnicspecific prevalence of peripheral arterial disease in the United States. Am J Prev Med, 2007; 32:328-33.

34. Ratanakorn D, Keandoungchun J, Tegeler CH. Prevalence and association between risk factors, stroke subtypes, and abnormal ankle brachial index in acute ischemic stroke. $\mathrm{J}$ Stroke. Cerebrovasc Dis. 2012; 21(6):498503.

35. Manzano J, Silva D, Pascual J, Chang $\mathrm{H}$, Wong $\mathrm{M}$, Chen $\mathrm{C}$. Associations of anklebrachial index $(\mathrm{ABI})$ with cerebral arterial disease and vascular events following ischemic stroke. Atherosclerosis, 2012; 04: 009.

36. Lee DH, Kim J, Lee HS, Cha MJ, Kim YD, Nam HS et al. Low ankle-brachial inde is a predictive factor for initial severity of acute ischaemic stroke. Eur J Neurol,2012; 19(6):892-8.

37. Sasaki $T$, Watanabe $M$, Nagai $Y$, Hoshi $T$, Takasawa M, Nukata M et al. Association of Plasma Homocysteine Concentration with 
Atherosclerotic Carotid Plaques and Lacunar Infarction. Stroke, 2002; 33: 1493-96.

38. Galal M and Zoheir N. Microalbuminuria and endothelaial dysfunction in hypertensive patients with and without cerebral lacunar infarctions. Sci. Med.J. ESCME, 2003; 15: 3.

39. Mlacak B, Blinc A, Pohar M, Stare J. Peripheral arterial disease and ankle-brachial pressure index as predictors of mortality in residents of Metlika County, Slovenia. Croat Med J,2006; 47(2):327-34.

40. Hanlon P, Byers $M$, Waker BR, Summerton $C$, Environmental and nutritional factors in disease: In NA Boon, NR College, BR Walker, JAA Hunter (Eds), Davidson principles \& Practice of Medicine, 20th Edn, New York, Churchill Livingstone, 2006; 578 - 581.

41. Jackson $C$ and Sudlow C. 'Are Lacunar Strokes Really Different? A Systematic Review of Differences in Risk Factor Profiles Between
Lacunar and Nonlacunar Infarcts', Stroke, 2005; 36:891-904.

42. Tsivgoulis G, Bogiatzi C, Heliopoulos I, Vadikolias K, Boutati E, Tsakaldimi S, et al. Low ankle-brachial index predicts early risk of recurrent stroke in patients with acute cerebral ischemia. Atherosclerosis, 2011; 220(2):407-12.

43. Aminur R, Quraishi FA. Miah MNA, Hakim M, Saha UK, Akteruzzaman M et al. Relationship between Homocysteine and carotid stenosis in ischaemic stroke, Bangladesh Journal of Neurosciences, 2012; 28(1):1-9

44. Tsai AW, Folsom AR, Rosamon WD, Jones DW. Ankle-brachial index and 7-year ischemic stroke incidence: the ARIC study. Stroke, 2001; 32(8):1721-4.

45. Ovbiagele, B. Association of ankle-brachial index level with stroke. J Neurol Sci,, 2009; 276(1-2)14-7. 